\title{
Construir o edifício documentário: concepções de Paul Otlet para uma ciência e uma técnica dos documentos
}

\section{Amanda Pacini de Moura}

Marilda Lopes Ginez de Lara

\author{
Bacharel em Biblioteconomia pela ECA (USP) \\ Bolsista de Iniciação Científica FAPESP (2011)
}

\begin{abstract}
Doutora em Ciências da Comunicação pela ECA (USP)

Professora livre-docente do Departamento de Biblioteconomia e Documentação da ECA (USP) Bolsista CNPq
\end{abstract}

O artigo apresenta as técnicas e propostas teóricopráticas desenvolvidas por Paul Otlet, para o tratamento de documentos, com propósito de recuperação e disseminação. Analisam-se o método documentário, responsável pela extração e disponibilização da informação documentada, e o conceito do repertório, elaborado para dispor e expor essa informação de maneira sintetizada, atualizada e acessível na Enciclopédia Documentária. Ressalta-se a importância das ideias subjacentes à proposta de Otlet, identificando-as particularmente nas figuras e metáforas adotadas por ele e na visão de mundo internacionalista, que sustentara a formação de suas ideias.

Palavras-chave: Paul Otlet; Documentação; Princípio monográfico; Classificação; Enciclopédia documentária; Internacionalismo.

\section{Building the documentary edifice: Paul Otlet's conceptions for a science and a technique for documents}

This paper presents the techniques and propositions, theoretical and practical, developed by Paul Otlet for retrieval and dissemination of documents. It analyzes the documentary method by which the information was extracted from documents and made available, and the concept of the repertory, conceived to dispose and expose 
information in a manner synthetic, current and accessible through the Documentary Encyclopedia. It emphasizes the importance of underlying ideas in Otlet's project, pointing particularly to their manifestation in the metaphors he adopted and in his internationalist worldview, which nourished the formation of his ideas.

\section{Keywords: Paul Otlet; Documentation; Monographic principle; Classification; Documentary encyclopedia; Internationalism.}

Recebido em 17.10.2012 Aceito em 10.12.2012

\section{Introdução}

Paul Otlet (1868-1944), advogado, bibliógrafo e internacionalista belga, é tido como um dos precursores da Ciência da Informação, por suas iniciativas para a organização da informação junto a Henri La Fontaine (1854-1943), senador belga e Prêmio Nobel da Paz em 1913. A proposta de Otlet, para a formação da ciência da Documentação ${ }^{1}$, construiu-se ao longo de quase 50 anos de trabalho bibliográfico, elaboração de normas e padrões para o trabalho com documentos e constituição de instituições de cooperação internacional.

Otlet era um internacionalista ou, para usar o termo que ele mesmo cunhou, um "mundialista" (MATTELART, 2002, p. 245), que acreditava na expansão das relações humanas além das fronteiras nacionais, como um determinismo sociológico, e na perfectibilidade da humanidade enquanto uma probabilidade dependente da adequada ordenação e articulação de habilidades, recursos e conhecimentos à disposição. A especialização das atividades decorrente da divisão mundial do trabalho resultaria na onipresença do documento enquanto intermediário das atividades e relações humanas, tornando a documentação, dessa maneira, um "campo privilegiado de ação" (MATTELART, 2002, p. 233) para os propósitos internacionalistas e, até mesmo, "instrumento de internacionalização" (OTLET, 1908 apud RAYWARD, 1975, p. 163), ferramenta sobre a qual as relações internacionais poderiam e deveriam ser construídas. Tratar de documentos, para ele, era tratar do conjunto de conhecimentos que neles encontram receptáculo e expressão e, por meio do conhecimento, tratar o próprio mundo.

Com estes fins, Otlet esboçou, explorou e aprimorou princípios que permitissem tratar adequadamente os conhecimentos registrados nos documentos, de modo a torná-los disponíveis e acessíveis a quem viesse a necessitar deles. Esse tratamento deveria se dar em dois âmbitos, que correspondiam à unidade do documento: conteúdo e suporte ou fundo e forma. O conhecimento depositado nos documentos deveria ser

\footnotetext{
1 Adotou-se a grafia documentação (minúscula) para fazer referência ao conjunto de documentos, e Documentação (maiúscula) para a ciência proposta por Otlet.
} 
adequadamente identificado, isolado e tornado independente das constrições de sua forma original de publicação e os próprios suportes e meios de divulgação e apresentação do conhecimento deveriam ser reestudados e retrabalhados de modo a dispor as informações de maneira mais adequada a sua compreensão e uso.

O presente artigo procura analisar o conjunto das técnicas e propostas pratico-teóricas desenvolvidas por Otlet com estes fins. Destaca-se, nesses desenvolvimentos, a centralidade do método documentário, estrutura de operações voltada à extração e disponibilização da informação documentada, ou fundo, assim como se enfatiza o papel do método em tornar possíveis as interferências na forma. Aponta-se, em seguida, o repertório enquanto modelo considerado ideal por Otlet quanto à forma, pois alcançaria o nível máximo de flexibilidade para a disposição da informação tornada possível pelo método documentário. A análise procura ressaltar as ideias que escoram as propostas otletianas, identificando-as particularmente nas figuras e metáforas adotadas por ele e na visão de mundo internacionalista que sustentara a formação de suas ideias.

Este estudo se justifica ao procurar contribuir para uma compreensão mais ampla quanto às contribuições de Otlet para a formação da Ciência da Informação, expondo as técnicas por ele propostas, de maneira articulada, entre si e ao ideário e à linguagem por ele adotados. Entende-se que o retorno às ideias de Otlet, assim como aos desenvolvimentos de outros protagonistas e precursores da Ciência da Informação, seja importante, não para que elas sejam de alguma maneira "resgatadas" ou "transferidas" para o presente, muito menos transformadas em mitos da área, mas, sim, para que o campo e seus conceitos possam ser percebidos como historicamente situados e moldados pelas trajetórias do passado.

\section{0 método documentário: fábrica e construção}

A base de todo o projeto de Otlet se situa sobre o conjunto de técnicas que ele denomina "método documentário" (INSTITUT INTERNATIONAL DE BIBLIOGRAPHIE [1907] ${ }^{2}$ 1990, p. 105), composto de duas etapas - a identificação de itens de informação pelo Princípio Monográfico e sua Classificação ${ }^{3}$, conforme os códigos da Classificação Decimal Universal (CDU) - e um fator orientador, a visão do conjunto (vue d'ensemble), que se apresenta ao longo de todo o processo. A própria configuração do método reflete a filosofia dos projetos de Otlet e,

\footnotetext{
2 Indicou-se, em parênteses, a data de publicação original dos textos, que foram editados em coletânea em 1990 , por W.B. Rayward, de modo a diferenciá-los uns dos outros.

${ }^{3}$ No original francês, Otlet usa dois termos distintos para identificar o esquema de classificação (classification) e a atividade de classificação (classement). A fim de evitar ambiguidade, optamos por diferenciá-las através da adoção da grafia maiúscula Classificação para classement e a minúscula classificação para classification. Nas traduções de textos já traduzidos do francês para o inglês, essa diferenciação ficou sujeita à nossa interpretação do contexto, pois a língua inglesa apresenta a mesma característica do português. Ressaltamos que todas as traduções de textos de língua estrangeira no artigo são livres, de nossa autoria.
} 
por meio de sua aplicação hipotética, ele desenvolve todas as suas construções teóricas posteriores.

Nesse sentido, é importante notar que a proposta de Otlet para o método documentário está estreitamente ligada a sua compreensão do método científico, sumarizada no Traité de documentation (1934), também em duas etapas:

[...] desmembrar os diversos fatores intervenientes no problema colocado e elucidar sucessivamente a influência de cada um tomado isoladamente [...] depois de ter estabelecido os fatos, agrupá-los em uma construção metódica ou sistema para descobrir as relações entre eles. Deve-se isolar os fatos para constatá-los, aproximá-los para compreendê-Ios (OTLET, 1934, p. 22).

O isolamento e a identificação dos fatos seriam obtidos por meio de sua observação, análise e catalogação e a construção de relações entre eles teria como objetivo final a enunciação de leis científicas. Ao mesmo tempo, em seu primeiro artigo relacionado à bibliografia, ele nota que:

[...] todo esse equipamento teria sido de pouca valia para 0 resultado final se todos os cientistas naturais [sic] em todas as partes do mundo civilizado, independentemente de seu número, não tivessem trabalhado com vistas à completude da mesma tarefa, a construção do mesmo edifício cujo perfil do projeto fora marcado em cada um deles (OTLET, [1891] 1990, p. 11-12).

Percebe-se que as etapas dos métodos documentário e científico são paralelas: desmembramento e isolamento, seguidos de aproximação e construção metódica, tendo como pano de fundo orientador um projeto de 'edifício' a construir. Sendo o propósito principal da atividade documentária justamente servir de apoio ao trabalho científico, segue-se que é da estrutura deste último que Otlet deduz seu método: ele questiona-se se "não [seria] possível imaginar uma resenha de livro que tenha sido desenvolvida "cientificamente" de acordo com procedimentos padronizados". Assim como o cientista desmembra os fatores que compõem seu problema para elucidá-lo, Otlet propõe que o texto científico possa ser objeto de um procedimento semelhante, em que os elementos ou fatores que o compõem sejam separados de maneira igualmente metódica, em categorias de elementos: "fatos, interpretação dos fatos, estatísticas, fontes". Em seguida, assim como o cientista agrupa os fatos obtidos desta análise para descobrir suas relações, os elementos dos textos poderiam ser semelhantemente reunidos, de acordo não mais com as perspectivas individuais do autor do texto, mas com "as diversas questões que a disciplina coloca" (OTLET, [1891] 1990, p. 16).

Em 1907, Otlet resumira a proposta de seu método da seguinte maneira: "O método documentário consiste em recorrer a documentos para extrair fatos e informação deles para a aquisição do conhecimento, para estudo ou pesquisa científica" (INSTITUT 
INTERNATIONAL DE BIBLIOGRAPHIE, [1907] 1990, p. 105). Identifica-se, aqui, a ideia fundamental de extração, de separação dos 'fatos e informação' da totalidade do documento. No Traité, Otlet detalha esse processo como a seleção de "cada elemento intelectual de um livro" e sua reinscrição em "um elemento material correspondente", uma folha ou ficha individual para cada elemento: é a aplicação do Princípio Monográfico. Dessa maneira, "obtém-se uma coincidência perfeita no documento entre unidade intelectual e unidade física do suporte escrito, entre divisão do pensamento e as seções do livro no concreto" (OTLET, 1934, p. 385-386). Assim unidos em 'coincidência perfeita', a dupla unidade documento/informação encontra-se disponível para ser manipulada física e intelectualmente.

Essa divisão modular do texto, tornando-o disponível à manipulação, é um dos traços que leva Rayward (1994, p. 236, grifo nosso) a explorar as relações entre as ideias de Otlet e os conceitos contemporâneos de hipertexto, apontando que o processo de "modularização do texto [...] corresponde de certo modo à maneira com que pensamos ideias, fatos e evidência", e acaba por tornar uma ideia "uma espécie de objeto manipulável". Ele nota que esse processo requer a definição de como e o que deve ser identificado como "nó ou aglomerado" hipertextual ou, adotando a linguagem do método documentário, quais parâmetros devem ser aplicados para identificação dos fatos a extrair. Rayward (1994) e Frohmann (2008) ressaltam a ausência de referências da parte de Otlet em relação à definição de tais parâmetros na aplicação do método:

[...] ele não demonstra nenhuma dúvida de que o que é fatualmente verdadeiro e de provável utilidade pode ser facilmente identificado. É apenas uma questão de institucionalizar certos processos para análise e organização do conteúdo dos documentos (RAYWARD, 1994, p. 247).

Ou seja, para Otlet, o isolamento de itens de informação é uma questão técnica, de 'institucionalizar processos': trata-se de aplicar um método desenvolvido 'cientificamente' e, assim, já previamente dotado de coerência teórica e metodológica, e organizar as instituições responsáveis pela aplicação e as relações entre elas.

Santos (2006, p. 89) identifica o Princípio Monográfico como "uma das contribuições mais importantes de Paul Otlet para a Documentação e posteriormente para a Ciência da Informação", observando que "obtêmse, com esses procedimentos, novos documentos que contêm informação também nova. Existe aqui, portanto, um duplo movimento: desmaterialização e virtualização de documentos e sua transformação em informação nova". Entende-se, dessa maneira, que Otlet diferencia e promove a separação de suporte e conteúdo, mas aponta, também, para a necessidade de amalgamá-los novamente para que sejam manipuláveis, desta vez conforme a lógica da unidade intelectual do conteúdo registrado. Esse processo geraria 'informação nova' na medida em que 
Otlet reconhece a influência da forma documental sobre o conteúdo da informação, mas trata-se de um 'novo' que já estaria potencialmente disponível no documento original, aguardando extração.

A ideia de 'extrair fatos e informação' dos documentos se repete na obra de Otlet, e alude à necessidade deles serem trabalhados e beneficiados antes do uso: para ele, "documentos constituem [...] materiais em estado bruto" (INSTITUT INTERNATIONAL DE BIBLIOGRAPHIE [1907] 1990, p. 108, grifo nosso). A figura da transformação mineral como metáfora para o trabalho documentário é explorada mais detalhadamente no Traité:

[...] é necessário por ordem nas 'montanhas' de papéis e documentos; é necessário criar uma 'metalurgia' do papel, criar acessos a essas montanhas, cujas encostas escondem tesouros, extrair o bom mineral e em seguida separar o metal puro da ganga (1934, p. 373-373bis).

Essa figura da extração evoca uma sugestão anterior de Otlet, em que ele propõe que a adoção "[d]o 'maquinário' apropriado" ([1920] 1990, p. 178) seja a solução adequada para tornar o conteúdo dos documentos mais acessível. Ressalta-se que se trata, aqui, de um 'maquinário' em sentido figurado, envolvendo instrumentos intelectuais, assim como equipamentos materiais, daí o método documentário.

A mesma metáfora ainda é repetida e expandida em ilustrações elaboradas por Otlet anos depois, na figura do Laboratorium Mundaneum, cujos processos configurariam uma "fábrica do conhecimento", conforme descreve Van den Heuvel (2008, p. 132):

Em uma imagem de uma fábrica do conhecimento chamada 'Laboratorium Mundaneum', ele apresenta as diferentes fontes de informação (livros, revistas, periódicos, estatísticas, etc.) como material bruto, sendo pulverizadas e peneiradas por um imenso amolador. O resultado, de acordo com uma nota no desenho, é 'a mais pura matéria útil para a civilização extraída de montanhas de documentos'. Os produtos ('elementos') desse processo mecânico de extração de documentos são classificados de maneira ordenada em diferentes vagões de classes do conhecimento, que são puxados pela locomotiva da CDU, e por esses meios esse conhecimento essencial é disseminado ao mundo externo.

Outro interesse da figura da fábrica é que ela implica na divisão do trabalho, que, conforme Otlet, é tanto um componente fundamental da aplicação do método documentário quanto uma razão para a existência do método: para ele, a divisão do trabalho é um fator presente não apenas no trabalho documentário e científico, mas em todos os âmbitos da vida 
humana; ela permite a colaboração entre todos e o acúmulo de esforços, multiplicando a capacidade de produção:

[...] o método documentário na verdade permite que se tenha a assistência de todos que trabalharam previamente os mesmos assuntos e seguir sua pesquisa até o ponto em que pararam. Assim ele torna a divisão do trabalho possível, e permite o pleno uso do que já foi descoberto (INSTITUT INTERNATIONAL DE BIBLIOGRAPHIE, [1907] 1990, p. 105).

Ainda na figura do 'Laboratorium Mundaneum', descrita acima por Van den Heuvel (2008), embora o foco seja o desmembramento promovido pelo Princípio Monográfico, também é descrita a segunda etapa do processo, a Classificação dos elementos 'em diferentes vagões de classes do conhecimento', para que estejam dispostos para uso. A etapa da Classificação promove a reinserção dos elementos purificados em uma nova estrutura, sintetizando-as, de modo que "todas as inconveniências inerentes [...] [à divisão em fichas] são evitadas" (OTLET; LA FONTAINE, [1895] 1990, p. 36). Conforme nota Santos (2006, p. 56), "O Princípio Monográfico promoveria a dispersão dos dados no sistema não fosse a presença de uma estrutura lógica representada pela CDU, que serviria tanto para organizar o armazenamento das informações como para recuperá-las". Dessa maneira, o sistema da CDU proveria novo contexto e localização aos itens que deles foram depurados pelo Princípio Monográfico.

A classificação funciona, de certa maneira, como o tal 'perfil do projeto' de 'edifício' referido anteriormente por Otlet, ao agrupar todos os documentos sob uma mesma perspectiva que se pretende: objetiva, impessoal e universal, em oposição à subjetividade autoral do material 'bruto', não tratado pelo método documentário.

\section{0 repertório: mapa e imagem do mundo}

Otlet inicia, em 1895, a aplicação do método documentário, formando o Repertório Bibliográfico Universal (RBU), catálogo em fichas que reuniria a bibliografia da totalidade da produção intelectual humana, de modo a constituir-se em um primeiro instrumento para o acesso universal ao conhecimento registrado. Nos anos seguintes, ele expande a proposta para além das referências bibliográficas, dando início ao Repertório Iconográfico Universal e ao Repertório Universal de Dossiês, gênese da proposta da Enciclopédia Documentária.

Em artigo publicado, ainda em 1895, Otlet e La Fontaine explicam e defendem sua proposta e seu método de trabalho e argumentam pela necessidade da construção do repertório:

A primeira tarefa que deve ser realizada, portanto, é a indexação das fontes bibliográficas existentes e a preparação de sua tabela completa, uma espécie de mapa bibliográfico 
integrado mostrando, além das regiões já exploradas, as que permanecem a ser descobertas. [...] Os esforços do Escritório4 para a unificação, no entanto, ajudarão a chamar a atenção dos pesquisadores especialmente para áreas que têm sido muito negligenciadas, e assim, gradualmente, os vazios no grande mapa bibliográfico desaparecerão ([1895] 1990, p. 39).

Essa é uma de várias ocasiões em que Otlet se refere à construção de repertórios por meio da figura da formação de um mapa. Em 1891, ao desenvolver suas primeiras reflexões sobre o trabalho documentário, ele havia sugerido uma analogia a partir da relação entre o trabalho dos exploradores e a construção de instrumentos geográficos:

O que seria mais fácil para um explorador do que conhecer precisa e instantaneamente as áreas às quais ele deve dirigir suas investigações se ele pretende agregar território novo ao mundo conhecido e explorado. Para determinar quais são as mais recentes descobertas, tudo que ele deve fazer é abrir um dos grandes mapas publicados pelas nossas sociedades geográficas. O que resta a ser descoberto é revelado a ele pela evidência recente. Confiando em seu guia, ele pode partir certo de não desperdiçar suas energias e recursos em expedições que já foram feitas e que são, portanto, inúteis para o avanço da ciência da geografia (OTLET, [1891] 1990, p. 13).

Otlet vê, no mapa, um instrumento sintetizador, que aglutina conhecimentos, gerando economia dupla de recursos para os geógrafos, que não têm de procurar informação em múltiplas fontes dispersas, assim como não correm o risco de se repetir em suas pesquisas, pois podem saber 'precisa e instantaneamente' o que aguarda investigação. As sociedades geográficas, por sua vez, obtêm, por meio dessas novas descobertas, as informações necessárias para atualizar seus mapas, que, em seguida, serão instrumento de trabalho para novos exploradores, que descobrirão novos lugares a mapear e, assim, sucessivamente. A proposta de Otlet é que a bibliografia ofereça exatamente o mesmo tipo de instrumento ao pesquisador, considerado um "explorador" dos "territórios" do conhecimento.

Note-se que a adoção e recorrência da metáfora do mapa indicam a existência de uma concepção desses "territórios" semelhante à adotada ao se trabalhar a representação do espaço físico. Para Otlet, a unidade intelectual do conhecimento é paralela à unidade física da Terra, pois a "enorme massa de documentos aparentemente desconectados" compartilha de uma natureza comum enquanto "produto da cooperação

\footnotetext{
${ }^{4}$ Refere-se ao Office international de bibliographie, órgão responsável pelo desenvolvimento do RBU.
} 
internacional para o desenvolvimento do conhecimento", assim como os territórios da Terra dividem o espaço do globo e conectam-se em continuidade espacial, tornando possível reuni-los em um único instrumento, o mapa: "Tal concepção unitária e sintética do conhecimento e da documentação sustenta a base do Repertório Bibliográfico Universal" (OTLET, [1903] 1990, p. 78).

O caráter dos mapas, enquanto instrumentos de organização e controle do espaço, que centralizam de maneira contínua, crescente e precisa elementos de informação sobre o território, claramente interessa a Otlet em suas referências a esses instrumentos. No entanto, identifica-se, também, a importância da capacidade de pluralidade desse instrumento, que reúne informações de gêneros distintos, tratando-as pela perspectiva do que eles têm em comum, o território. De maneira paralela, por meio de um traço universal dos documentos - sua natureza comum enquanto produtos do conhecimento humano - torna-se possível reunir no repertório uma pluralidade de informações de origens e formas distintas.

Isso aponta, também, para o caráter de abertura do mapa, sua disponibilidade de agregar novas evidências: um mapa nunca se torna plenamente completo, nunca atinge o ponto de fechamento, pois sua completude seria se tornar uma perfeita duplicata do espaço que representa. Mesmo que esse seja sempre seu potencial, nunca é uma realização. Note-se, inclusive, que esse potencial de constituição de um 'duplo' do mundo é uma ideia que ocorre ao próprio Otlet ao referir-se à natureza dos documentos, que permitem "uma reprodução, uma cópia do mundo" ao constituírem a materialização do pensamento, configurando "uma nova realidade, distinta de todas as outras" (OTLET, 1934, p. 425).

Nos "mapas" de Otlet, os repertórios, ele busca fugir à arbitrariedade da divisão por páginas e cadernos do formato livro, desenvolvendo, por meio das fichas do método documentário, uma técnica que sobreponha material e intelectual, de modo a propiciar a manipulação das ideias e dos documentos. Com isso, ele pretende multiplicar ao infinito as possibilidades de trabalho sobre eles, de modo que o livro nunca seja considerado fechado ou concluído (OTLET, 1934).

Ressalte-se que isso não acontece apenas pela mudança de suporte e tratamento material, mas pelo procedimento intelectual que esse suporte implica: Otlet relaciona a estrutura do livro encadernado tradicional à subjetividade autoral que se impõe às ideias apresentadas, pois é um sistema em que as ideias podem ser elaboradas por um número limitado de pessoas. O modelo do repertório em fichas permitiria potencialmente o oposto, sendo perpetuamente aberto à intervenção de múltiplos autores. Dessa maneira, seria cada vez menos pessoal, mais democrático e objetivo, "guarda[do] contra qualquer limitação, exclusivismo ou tendência" (INSTITUT INTERNATIONAL DE BIBLIOGRAPHIE, [1907] 1990, p. 109).

O argumento de Otlet, que associa a construção coletiva à objetividade, se baseia na convicção de que a reunião de todos os pontos de vista seria plenamente capaz de alcançar uma representação fiel e objetiva da realidade, em que as contradições e repetições internas são 
anuladas (DAY, 1997; DUCHEYNE, 2009; OTLET, 1934,). A aplicação rigorosa das metodologias científica e documentária de trabalho bastaria, assim, para que os repertórios resultassem em um "novo livro", livre de subjetividade, sendo dotados dessa maneira de um potencial verdadeiramente democrático, ao reunir o melhor da centralização e da pluralidade, da síntese e da análise.

\section{A Enciclopédia Documentária: em busca de novas linguagens}

O repertório que realizaria toda essa potencialidade do formato, porém, não seria o RBU: Otlet prevê a necessidade de se "completa[r] o edifício documentário" (OTLET, [1920] 1990, p. 197) pela constituição da Enciclopédia Documentária, instrumento que "opera sobre seus elementos [dos Livros e Documentos] para formar novos conjuntos onde eles são distribuídos, coordenados e dispostos nos quadros de formato unificado e de uma classificação única" (OTLET, 1934, p. 409, grifo nosso). A Enciclopédia Documentária:

[...] será contínua, cooperativa do ponto de vista documentário, ilustrada, universal e internacional. Recapitulará o produto da ciência e da vida que está em livros, e o disporá em "formatos documentários", ou seja, de acordo com os arranjos intelectuais e físicos que atendam melhor a necessidades reconhecidas dos usuários (OTLET, [1920] 1990, p. 195).

Desde o início de seus trabalhos bibliográficos, Otlet refletira sobre essas 'necessidades reconhecidas dos usuários', de identificar as produções recentes realizadas nas diferentes áreas do saber e, com isso, diagnosticar o estado das diversas questões científicas, de modo a trabalhar a partir do ponto indicado por elas. Ele discutira, também, o fator da alteração das práticas de leitura e busca de informação dos pesquisadores, que, no lugar de acompanhar o corpo de publicações e a linha de pensamento de um mesmo autor, adotam uma leitura menos intensiva, distribuindo seu tempo de pesquisa por textos diversos: "Antes se lia; hoje se confere, checa, verifica. [...] Obras são cotejadas, isto é, vai-se a elas para buscar uma resposta a perguntas muito específicas e especializadas" (OTLET, [1891] 1990, p. 79). A busca por melhor atender a essas necessidades traduz-se na exploração de novas formas de apresentação dos elementos de informação.

No Traité, Otlet detalha o processo de operação sobre esses elementos na formação da Enciclopédia Documentária, iniciando-se pela reunião em dossiês dos itens de informação classificados sob a mesma notação da CDU, ou seja, relacionados a uma mesma questão científica. Com isso pretendia a centralização da informação dispersa, abreviando o tempo de consulta, leitura e crítica dos documentos: 
Eles [os dossiês] permitem, por assim dizer, de maneira automática, apreender as coisas mais objetivamente e em sua totalidade; cada documento considerando um ponto de vista, a realidade total sendo composta do conjunto desses pontos de vista (OTLET, 1934, p. 409-410, grifo nosso).

As etapas subsequentes de formação da Enciclopédia retrabalhariam progressivamente esses itens de informação, procurando aprimorar esse potencial de 'apreensão automática, objetiva e total' da informação, que Otlet identifica nos dossiês. Estes seriam transformados em um Atlas ${ }^{5}$ Enciclopédico, composto de quadros padronizados e classificados, nos quais se distribuiriam os dados para melhor leitura e análise. Otlet (1934, p. 410) argumenta que: "O quadro é o meio gráfico de apresentar os dados ao espírito do modo mais fácil, mais rápido, mais completo. [...] Com o quadro um modo de expressão novo das ideias é criado. As formas criadas podem ser generalizadas e gerar outros quadros".

Trata-se, assim, de configurar sínteses visuais do conhecimento que, como o mapa das sociedades geográficas, basta abrir para conhecer, 'do modo mais fácil, mais rápido, mais completo', de forma mais 'automática, objetiva e total'. Mais que isso, a configuração do quadro é, para Otlet, continuamente sintetizadora, permitindo a progressiva generalização das informações dispostas em novos quadros, num movimento constante em direção à codificação final ${ }^{6}$.

Van den Heuvel (2008, p. 132-133) afirma que:

Imagens, esquemas e diagramas não eram apenas uma forma concisa e informativa de apresentar acúmulos de dados; para Otlet eles poderiam ser entendidos como constituindo a gramática de uma linguagem universal para o intercâmbio do conhecimento.

Nesse aspecto, apontamos que o caráter de 'linguagem universal' que Otlet assinala nas imagens, ele também identifica na CDU (OTLET, 1934; RAYWARD, 1975), esta por recorrer à universalidade dos números, aqueles por seu caráter gráfico. Quadros e números, ambos diferenciamse das linguagens verbais naturais, circunscritas a limitações nacionais e, dessa maneira, subjetivas e inadequadas para a representação universal requerida da documentação e da ciência. Ainda, por ultrapassarem essas circunscrições e limitações locais, Otlet vê na Enciclopédia Documentária e na CDU instrumentos de visualização universais, capazes de serem compreendidos além de barreiras culturais e linguísticas (VAN ACKER, 2011; VOSSOUGHIAN, 2003). Desse modo, elas se caracterizariam como

\footnotetext{
5 Van Acker (2011) e Van den Heuvel e Rayward (2011) ressaltam que, na língua francesa, a palavra atlas refere-se não apenas a mapas geográficos, mas a um conjunto de recursos visuais (imagens, reproduções, tabelas, esquemas, etc.), preparados para facilitar a compreensão de uma obra textual.

${ }^{6}$ Otlet refere-se ao estágio final da Enciclopédia como "Codificação Enciclopédica" (OTLET, 1934, p. 411), sem definir as características formais que diferenciariam a codificação do atlas, contentando-se em apresentar o nível conceitual a ser alcançado. Infere-se assim que as formas que a codificação viria a tomar decorreriam das explorações realizadas por Otlet, no Atlas Enciclopédico.
} 
linguagens ideais para um trabalho de caráter universal como o trabalho documental.

A universalidade que Otlet defende para o trabalho documental não se relaciona apenas com suas ambições organizacionais, mas ao que ele identifica como a própria natureza do objeto científico da Documentação: os documentos, onipresentes ou universais nas relações humanas, e o conhecimento registrado neles, considerado intrínseca e universalmente válido, pois representativo da realidade objetiva. Enquanto disciplina científica, a Documentação constituir-se-ia simultaneamente especializada e universal: seria responsável por uma etapa específica do trabalho intelectual que é a lida com os documentos, mas assim como estes estaria presente em todos os níveis e áreas de atividade humana.

Otlet identifica na onipresença dos documentos uma decorrência da especialização das atividades pela divisão do trabalho, os documentos, tornando-se intermediários de comunicação entre os homens no tempo e no espaço. Isso acarretaria o crescimento da interdependência entre nações e indivíduos, mas, ao mesmo tempo, dificultaria o reconhecimento desses vínculos, pois a realização apenas de etapas específicas obliteraria a visão do todo. Em nível global, o desequilíbrio desses fatores alimentaria conflitos e poria em cheque a paz mundial; no trabalho científico, promoveria a repetição de esforços e atravancaria os avanços da ciência. Tornar-se-ia necessário, então, integrar a produção documental dessas atividades dispersas, dispondo e expondo sua unidade intrínseca de maneira amplamente acessível.

Otlet adota a figura da construção do edifício para representar o processo de construção coletiva do conhecimento, buscando equilibrar a liberdade individual de pesquisa e a necessidade de cooperação coletiva do grupo:

Cada um traz para o edifício comum a pedra que ele mesmo escavou. É importante, no entanto, que a pedra seja aparada para as dimensões do espaço que deve ocupar ao lado das outras, e consequentemente que o estado de desenvolvimento do conjunto do trabalho seja sempre exata e facilmente conhecido (OTLET; LA FONTAINE, [1895] 1990, p. 27).

Nota-se que cada um é livre em seu trabalho, pois traz 'a pedra que ele mesmo escavou', bruta, mas deve coordenar esforços e sujeitar-se à disponibilidade de encaixe do conjunto, para 'que a pedra seja aparada', tratada conforme as normas estabelecidas. Ilustra-se assim a convicção de Otlet de que a aplicação rigorosa das metodologias científica e documentária bastaria para que os repertórios resultantes do trabalho documentário resultassem em um produto livre da subjetividade característica das obras individuais.

Frohmann (2008), no entanto, aponta que a importância dada por Otlet à subjetividade intrínseca do documento 'bruto' implica em contradição quanto à suposta objetividade da informação extraída, pois se 
percebe que o processo de extração não basta para a identificação dos elementos de informação: "a plena revelação dos fatos" ( $p$. 79) só sendo atingida quando os elementos são dispostos na estrutura de classificação. Desse modo, ele aponta que o próprio caráter do fato, enquanto item de informação objetiva, estaria sujeito ao estabelecimento de sua relação com outros fatos, pondo em questão a própria tentativa de isolá-lo da qual o método documentário depende.

O raciocínio do autor evidencia a insuficiência das figuras da extração mineral e da construção do edifício para dar conta da complexidade acarretada pelo trabalho com a informação e os documentos, tanto para a atividade bibliográfica-documental que tem neles seu objeto, quanto para a atividade científica que tem neles seus instrumentos.

Ainda assim, justamente essa contradição entre a suficiência do fato isolado e sua necessidade de Classificação explica a preocupação de Otlet com o desenvolvimento de novos meios de se trabalhar não apenas o conteúdo extraído dos documentos, mas sua disposição e arranjo. Entende-se, inclusive, que parte da ênfase dada por Otlet às novas mídias de seu tempo, deve-se à capacidade que ele identifica nelas de atender à demanda colocada pela Documentação de propiciar 'de maneira automática apreender as coisas mais objetivamente e em sua totalidade'. Embora um componente da atração das novas tecnologias fosse seu potencial de solução técnica estrita para fins de multiplicação e distribuição de documentos, os mecanismos distintos de que elas dispunham para a apreensão do conhecimento são importantes no processo que leva Otlet a considerá-los "substitutos do livro". A linguagem visual, em particular, "fala ao cérebro pelos olhos" e "suprime o esforço de interpretação" (OTLET, 1934, p. 223-224).

Van Acker (2011, p. 36) defende que essa abertura de Otlet às novas mídias origina-se na raiz de seu pensamento sobre a documentação:

Com a noção de documentação, Otlet abandonou o livro como mídia privilegiada para a disseminação de ideias e afirmou no lugar a importância da multiplicidade e a possibilidade da combinação de mídia textual e visual.

Em vez de ver todas as mídias existentes como diferentes registros do conhecimento, ele considerou-as como corporificações documentárias de um único corpo de conhecimento enciclopédico (grifo nosso).

Dessa maneira, ao pensar a questão da bibliografia e da dispersão dos fatos nas montanhas de documentação, Otlet já prenuncia um envolvimento com todos os tipos de mídia, a dispersão do conhecimento não dizendo respeito apenas à quantidade de documentos produzidos, mas à multiplicidade de formas em que eles se apresentam. Van den Heuvel e Rayward (2001, p. 3) afirmam que: 
Otlet estava plenamente consciente de que reconceitualizar o formato livro como base para uma nova espécie de representação do conhecimento criada colaborativamente exigiria repensar como nós deveríamos interagir com os processos e técnicas de produção e disseminação do conhecimento.

Entende-se que nesse 'repensar' incluem-se não apenas as possibilidades que Otlet apresenta no repertório, na Enciclopédia e nos sistemas de classificação, como formas para integração do 'corpo de conhecimento enciclopédico', mas repensar as próprias 'corporificações documentárias' já existentes e vislumbradas, compreendendo-as e explorando-as plenamente como unidades documentárias.

\section{Considerações finais}

Os desenvolvimentos de Paul Otlet para o trato dos documentos com vistas à construção da ciência da Documentação são extensos, tanto do ponto de vista teórico quanto de iniciativas práticas e institucionais. Na base de todos eles, no entanto, identifica-se a mesma preocupação internacionalista de prover, por meio da ação junto aos documentos, a comunicação entre os homens através das fronteiras físicas, culturais e linguísticas.

A compreensão de Otlet quanto à importância do processo de divisão internacional do trabalho, que considera o potencial positivo do aumento exponencial da produção de conhecimento assim como os riscos de desintegração e conflito que o desequilíbrio da divisão propicia, sustenta a formulação de suas propostas.

O método documentário, pelo qual se propõe a extração, isolamento e classificação dos fatos dos documentos, constitui a técnica intelectual básica do tratamento documental, segundo Otlet, e o repertório em fichas, o novo modelo de formato para disposição e acesso à documentação integrada. Com esses instrumentos, Otlet pretendia constituir uma técnica de trabalho documental que favorecesse a construção organizada, coletiva e objetiva do conhecimento, em oposição à dispersão da produção de intelectual. Ao mesmo tempo em que amplia o escopo do que deve ser considerado parte do universo da documentação, sua proposta frisa a necessidade de se desenvolver meios e linguagens universais para a visualização desse conjunto documental de forma integrada.

\section{Referências}

DAY, R. E. Paul Otlet's Book and the Writing of Social Space. Journal of the American Society for Information Science, v. 48, n. 4, p. 310-317, 1997. 
DUCHEYNE, S. "To treat of the world": Paul Otlet's ontology and epistemology and the circle of knowledge. Journal of Documentation, v. 62, n. 2, p. 223-244, 2009.

FROHMANN, B. The Role of Facts in Paul Otlet's Modernist Project of Documentation. In: RAYWARD, W. B. (Ed.). European modernism and the information society: informing the present, understanding the past. Aldershot, UK: Ashgate, 2008. p. 75-88.

INSTITUT INTERNATIONAL DE BIBLIOGRAPHIE. The systematic organisation of documentation and the development of the International Institute of Bibliography. [1907]. In: RAYWARD, W. B. (Ed.). International Organisation and Dissemination of Knowledge: selected essays of Paul Otlet. Amsterdã: Elsevier, 1990. p. 105-111.

MATTELART, A. História da utopia planetária. Porto Alegre: Sulina, 2002.

OTLET, P. Something about bibliography. [1891]. In: RAYWARD, W.B. (Ed.). International Organisation and Dissemination of Knowledge: selected essays of Paul Otlet. Amsterdã: Elsevier, 1990. p. 11-24.

OTLET, P. The International Organisation of Bibliography and Documentation. [1920]. In: RAYWARD, W.B. (Ed.). International Organisation and Dissemination of Knowledge: selected essays of Paul Otlet. Amsterdã: Elsevier, 1990. p. 173-203.

OTLET, P. The Science of Bibliography and Documentation. [1903]. In: RAYWARD, W.B. (Ed.). International Organisation and Dissemination of Knowledge: selected essays of Paul Otlet. Amsterdã: Elsevier, 1990. p. 71-86.

OTLET, P. Traité de documentation: le livre sur le livre: teórie et pratique. Bruxelas: Éditiones Mundaneum, 1934.

OTLET, P.; LA FONTAINE, H. Creation of a Universal Bibliographic Repertory: a preliminary note. [1895]. In: RAYWARD, W.B. (Ed.). International Organisation and Dissemination of Knowledge: selected essays of Paul Otlet. Amsterdã: Elsevier, 1990. p. 25-50.

RAYWARD, W. B. Visions of Xanadu: Paul Otlet (1868-1944) and hypertext. Journal of the American Society for Information Science, v. 45, n. 4, p. 235-258, abr. 1994.

RAYWARD, W. B. The Universe of Information: the work of Paul Otlet for Documentation and International Organization. Moscou: VINITI, 1975.

SANTOS, P. D. M. L. O ponto de inflexão Otlet: uma visão sobre as origens da Documentação e o processo de construção do Princípio Monográfico. 2006. 146 f. Dissertação (Mestrado em Ciência da Informação) - Escola de Comunicações e Artes, Universidade de São Paulo, São Paulo, 2006. 
VAN ACKER, W. Internationalist utopias of visual education: the graphic and scenographic transformation of the Universal Enyclopaedia in the work of Paul Otlet, Patrick Geddes, and Otto Neurath. Perspectives on Science, v. 19, n. 1, p. 32-80, 2011.

VAN DEN HEUVEL, C. Building society, constructing knowledge, weaving the web: Otlet's visualizations of a global information society and his concept of a universal civilization. In: RAYWARD, W. B. (Ed.). European modernism and the information society: informing the present, understanding the past. Aldershot, UK: Ashgate, 2008. p. 127-153.

VAN DEN HEUVEL, C; RAYWARD, W. B. Facing interfaces: Paul Otlet's visualizations of data integration. Journal of the American Society for Information Science and Technology, v. 62, n. 12, p. 2313-2326, 2011.

VOSSOUGHIAN, N. The language of the world museum: Otto Neurath, Paul Otlet, Le Corbusier. Transnational Associations/Associations Transnationales, v. 1-2, p. 82-93, 2003. 